\title{
DIMENSÕES SOCIAIS DA VIDA NO PROCESSO DE SAÚDE/DOENÇA: UMA ANÁLISE SOBRE A CIRURGIA BARIÁTRICA
}

\begin{abstract}
Francielle Lopes Alves
Doutoranda em Serviço Social, Universidade Federal de Santa Catarina, francialves@hotmail.com Moara Monteiro Sant'Helena Mestranda em Enfermagem, Universidade Federal de Santa Catarina, moara15@hotmail.com Mayara Gelsleichter Assistente Social, Universidade Federal de Santa Catarina, mayarapetsso@gmail.com Letícia Possamai Della Acadêmica do Curso de Serviço Social, Universidade Federal de Santa Catarina, leticia.pdella@gmail.com
\end{abstract}

\section{RESUMO}

A obesidade é um fenômeno que ocorre na humanidade desde muito tempo, porém sua dimensão nunca havia alcançado proporções tão grandes como é a atual (MOURA; PASCHOAL, 2009). As causas para explicar esse aumento tão importante no número de obesos no mundo estão ligadas a inúmeros fatores, como as mudanças no estilo de vida, a questão genética e os hábitos alimentares. Ao considerar que o sobrepeso e a obesidade tornaram-se problemas de saúde no Brasil, desenvolveram-se políticas, açóes e programas públicos para reverter este quadro de maneira individual e populacional. Neste espaço, a cirurgia ba- 
riátrica emerge como prática para reverter este cenário da obesidade (DINIZ et al., 2008). Após a realização do procedimento cirúrgico, várias dimensões sociais da vida do indivíduo são modificadas, como vínculo empregatício, organização familiar, relaçóes sociais, hábito alimentar e recursos financeiros. Ao saber da importância de cada esfera social, ressalta-se a necessidade da discussão, por compreender que elas interferem diretamente no processo saúde/doença do indivíduo. Diante disso, este trabalho busca compreender a cirurgia bariátrica não somente como uma alteração biológica, mas analisar as mudanças que ocorrem a partir da realização do procedimento, uma vez que ela afeta a vida social, profissional, familiar, econômica e social do indivíduo, dando legitimidade aos novos e velhos significados sociais que permeiam essas esferas. A obesidade é uma condição crônica, com origem multifatorial. O seu tratamento envolve várias abordagens (nutricional, uso de medicamentos e prática de exercícios físicos). Entretanto, vários pacientes não respondem às práticas terapêuticas, necessitando de uma intervenção mais eficaz. Frente a isso, a cirurgia bariátrica apresenta-se como uma técnica de grande auxílio nos casos de obesidade, e sua indicação vem crescendo nos dias atuais (FANDIÑO et al., 2004). Construir uma vida mais saudável é o resultado esperado pelas pessoas que realizam a cirurgia, mas este é um processo muito complexo, pois aspectos físicos, psíquicos e sociais são envolvidos, além de variar de indivíduo para indivíduo. Com a realização do procedimento cirúrgico, mudanças ocorrem nas esferas sociais que permeiam sua vida e, assim, cabe ao indivíduo reestruturar-se nessa nova condição, levando em consideração suas limitaçóes e potencialidade vivenciadas em seu processo de saúde/doença. A família sempre foi um elemento central no desenvolvimento do bem-estar dos seus integrantes, porém, na atualidade, vem sendo ainda mais requerida para assumir a função de parceira do sistema de saúde. A partir dos anos 1990, a política de saúde passou a referenciar a família, incorporando diretrizes oficiais que fizessem menção à família, abordando o processo do cuidado. Dessa forma, elas foram incorporadas pelos serviços de saúde, alterando consequentemente a organização e a provisão do cuidado em saúde (BARCELOS, 2011). Já Minuchin et al. (1999) abordam a ideia de que a família se reestrutura quando passa por momentos de transição; algumas são decorrentes do ciclo normal da vida e outras são oriundas 
de eventos inesperados que podem ocorrer em qualquer ciclo familiar. Sendo assim, a família se reorganiza para dar suporte aos membros que se encontram doentes e fragilizados, por meio da flexibilidade e adaptabilidade dos integrantes. A realização de um procedimento cirúrgico implica também o afastamento do trabalho. Após a cirurgia bariátrica, o paciente permanece 90 dias em casa, no processo de recuperação, e, assim, dependendo do vínculo empregatício, esse afastamento pode vir a comprometer a renda familiar e, consequentemente, o sustento dos seus membros. Na sequência do procedimento cirúrgico, metade das pessoas obesas volta a engordar parcialmente e 5\% retornam ao peso anterior a cirurgia. Desse modo, a mudança náo está apenas em submeter-se à cirurgia bariátrica, é preciso mudança de hábitos e reeducação alimentar para o resto da vida. No entanto, percebe-se que a implementação de um novo hábito alimentar reflete no aspecto financeiro e familiar, cabendo mais uma vez à família articularse para manutenção das necessidades, pensando na prevenção e na promoção da saúde de seu membro. Em cada indivíduo, entrelaça-se de modo particular uma série de relaçóes sociais. $\mathrm{O}$ caráter social dos sujeitos implica uma relação entre o indivíduo e a comunidade, ou seja, os meios que os rodeiam. Para entender a comunidade da qual o sujeito social é participante, é necessário compreender a dimensão social que a permeia. De acordo com Iamamoto (2003), a questão social é entendida como o conjunto das expressóes das desigualdades da sociedade capitalista. Essas desigualdades presentes na sociedade atual desencadeiam uma série de outras consequências que resultam em formas da exclusão. Cabe ressaltar essas mudanças como expressóes da questáo social, tendo a visão do sujeito com um cidadão que possui direitos e que tem os mesmos afastados em virtude da condição de saúde fragilizada. A obesidade é uma doença crônica, que apresenta consequências físicas, psicológicas, sociais e econômicas, decorrente de inúmeros fatores que têm reflexos extremamente graves e cada vez mais crescentes. Apesar de diminuir a expectativa de vida do usuário, hoje a obesidade atinge uma proporção tão elevada que é considerada um problema de saúde pública, e a cirurgia bariátrica aparece neste contexto como prática para revertê-la. Ao mesmo tempo em que é dever do Estado a proteção social com os cidadãos, é delegada à família esta responsabilidade, expressa em diversas legislações. Mesmo não possuindo 
condições de manter esta proteção, a família ainda é a responsável pela provisão de recursos materiais, financeiros e emocionais, sendo muitas vezes culpabilizada pela situação em que se encontram seus integrantes. Vivenciamos um tempo em que se valoriza o reconhecimento da instância familiar como fonte de cuidado com que seus membros podem contar, tendo cada vez menos o suporte público, o qual deveria garantir o bem-estar dos usuários. Por vezes, quando não há a presença da família, recai às relaçóes sociais o amparo desse indivíduo. Decorrente de que nem sempre as políticas públicas atendem às necessidades básicas da população, os usuários têm de desenvolver estratégias próprias para dar resolutividade às suas demandas, seja na dimensão econômica, com a manutenção de novas despesas, ou na articulação para o afastamento do trabalho, quando o indivíduo o tem. As demandas que surgem da temática, por apresentarem caráter social, exigem um olhar coletivo e político, pois envolvem valores e ética, no sentido da relação entre os homens. Hoje é visível o crescimento de uma epidemia da obesidade, a qual é considerada um problema de saúde pública. Com isso, exige-se uma relação e ação multi/interdisciplinar. Ao Estado, que atua como gestor das políticas sociais, cabe não só o alerta social sobre a crescente demanda, mas a efetiva proteção dos seus cidadãos.

Palavras-chave: Obesidade; Cirurgia Bariátrica; Redes Sociais.

\section{REFERÊNCIAS}

BARCELOS, M. S. A incorporação da família nos serviços de saúde: um debate a partir das concepçóes dos profissionais num hospital de alta complexidade. 2011. 169 f. Dissertação (Mestrado em Serviço Social) - Universidade Federal de Santa Catarina, Florianópolis.

DINIZ, M. F. H. S. et al. Perfil de pacientes obesos classe III do Sistema Público de Saúde submetidos à gastroplastia em "Y de ROUX", no Hospital das Clínicas da UFMG: altas prevalências de superobesidade, co-morbidades e mortalidade hospitalar. Revista Médica de Minas Gerais, Belo Horizonte, v.18, n.3, p.183$190,2008$. 
FANDIÑO, J. et al. Cirurgia bariátrica: aspectos clínico-cirúrgicos e psiquiátricos. Revista de Psiquiatria do Rio Grande do Sul, Porto Alegre, v.26, n.1, p.47-51, 2004.

IAMAMOTO, M. V. O Serviço Social na contemporaneidade: trabalho e formação profissional. São Paulo: Cortez, 2003.

MINUCHIN, P. et al. Trabalhando com famílias pobres. Porto Alegre: Artes Médicas Sul, 1999.

MOURA, M. D. G.; PASCHOAL, M. A. Análise da variabilidade da frequência cardíaca em meninos e meninas não obesos, obesos e obesos mórbidos. IN: XIII ENCONTRO DE INICIAÇÃO CIENTÍFICA, 2009, Campinas. Anais... Campinas: Pontifícia Universidade Católica de Campinas, 2009. 